\title{
Biogas Plants Site Selection integrating Multicriteria Decision Aid Methods and GIS Techniques: A Case Study in a Portuguese Region
}

\author{
Sandra Silva $\left({ }^{\mathrm{a} b}\right)$, Luís Alçada-Almeida $\left({ }^{\mathrm{b} c}\right)$, Luís C. Dias $\left({ }^{\mathrm{b} c}\right)$ \\ $\left({ }^{a}\right)$ Polytechnic Institute of Viana do Castelo, Praça General Barbosa 4900-347, Viana \\ do Castelo, Portugal \\ Tel.: +351258 809 610; Fax: +351258 829 065; E-mail:sandrasilva @esa.ipvc.pt \\ $\left({ }^{b}\right)$ Institute for Systems Engineering and Computers, Rua Antero de Quental, No 199 , \\ 3000 - 033 Coimbra, Portugal. \\ (c ) Faculty of Economics, University Coimbra, Av. Dias da Silva, 165, 3004-512 \\ Coimbra, Portugal
}

This is a PDF file of an unedited manuscript that has been accepted for publication in Biomass and Bioenergy.

The manuscript will undergo copyediting, typesetting, and review of the resulting proof before it is published in its final form. Please note that during the production process errors may be discovered which could affect the content, and all legal disclaimers that apply to the journal pertain. The final version will be available at:

https://doi.org/10.1016/j.biombioe.2014.10.025

\section{Abstract}

This work addresses the problem of determining the most suitable sites for locating biogas plants using dairy manure as feedstock, specifically in the Entre-Douro-e-Minho Region in Portugal. A Multicriteria Spatial Decision Support System is developed to tackle this complex multicriteria decision-making problem, involving constraints and many environmental, economic, safety, and social factors. The approach followed combines the use of a Geographic Information System (GIS) to manage and process spatial information with the flexibility of Multicriteria Decision Aid (MCDA) to assess factual information (e.g., soil type, slope, infrastructures) with more subjective information (e.g., expert opinion). The MCDA method used is ELECTRE TRI, an outranking-type method that yields a classification of the possible alternatives. The results of the performed analysis show that the use of ELECTRE TRI is suitable to address real-world problems of land suitability, leading towards a flexible and integrated assessment.

Keywords: Siting problem, Location analysis, Land-Use Suitability, Multiple Criteria, Spatial Decision Support Systems, ELECTRE TRI. 


\section{Introduction}

Livestock farms produce excreta in large quantities, which traditionally have been used directly as manure to fertilize the land. However, in some cases, the disposal methods can cause environmental problems such as odour and water pollution [1]. There is growing interest in installing Anaerobic Digester (AD) to use dairy manure as a biomass resource for both economic value and environmental benefit [2,3]. An AD energy system promotes methane production, captures and converts it into electricity and heat, and also yields a fertilizer.

Biomass is part of Portugal's renewable primary sources, but in 2008 the relative contribution of Portuguese biogas for the biomass primary energy consumption did not reach $1 \%$ [4]. This factor together with the high biogas potential of Portugal shows that this important sector has been somewhat neglected [5].

To promote the development of dairy manure-based bio-energy systems it is essential to find suitable locations for such development [3]. Land-use suitability analysis is a tool used to identify the most suitable places for locating future land uses according to specific requirements, preferences, or predictors of some activity [6]. Determining suitable land for a particular use is a complex process involving multiple aspects that may relate to biophysical, socio-economic and technical aspects [3].

Choosing an appropriate location for a biogas plant is a task for which Geographic Information Systems (GIS) and Multicriteria Decision Aid (MCDA) are helpful [7,8,9,10]. MCDA provides significant support for the generation and comparison of alternatives taking into account the evaluation criteria through an active participation of experts and stakeholders involved in the decision-making process. MCDA offers as set of procedures, techniques and algorithms for structuring decision problems, and designing, evaluating and prioritizing decision alternatives $[11,12]$. Location problems have strong spatial dimensions, as a large number of spatial variables are involved, such as the proximity to rivers, roads or populations, and spatial characteristics of the region including geology, slope, and soil types among others. GIS are designed to store, manage, analyse and visualize geospatial data required by decision-making processes [13].

A large number of papers concerning multicriteria suitability analysis and GIS have been published (see $[14,15,16,17,18,19])$. More recently, GIS has been combined with MCDA in environment/ecology (e.g. [20,21]), in undesirable facilities location (e.g. [22,23,24]), energy $([25,26])$, and location $([27,28])$, among other application areas.

In this context, a specific family of Decision Support Systems (DSS) named Multicriteria Spatial Decision Support Systems (MC-SDSS) may provide effective support. MC-SDSS typically includes a set of geographically defined alternatives from which a choice, a ranking or a classification of a set of alternatives is made with respect to a given set of evaluation criteria [17].

In this paper, a spatial multicriteria approach for supporting decision-makers in the process of locating of biogas plants is proposed. Spatial multicriteria analysis requires information on the value of the criteria and geographical location of the alternatives, in addition to the preferences of decision makers. A variety of constraints, as well as economic, environmental and social factors are integrated in this approach to help determine the most suitable sites for installing such bio-energy systems. As an application of the approach proposed in this work, a land suitability map for locating biogas plants was developed for the Entre-Douro-e-Minho (EDM) region in Portugal. The result is a classification of each potential location into one of three categories of suitability: low, medium, or high suitability. 


\section{Methodology}

The MC-SDSS developed for the present study is shown in Figure 1, encompassing the three phases: intelligence, design and choice, according to the model proposed by [29]. In the intelligence phase, data is acquired, processed, and an exploratory data analysis is performed. This phase focuses on structuring the problem after which the objectives to pursue are explored and the evaluation criteria or attributes are selected. The design phase involves data collection and processing, as well as the development of multicriteria analysis through the definition of the relationships between objectives, attributes and preferences of the decision maker [12]. In this phase, specific decision rules are used to evaluate and sort alternatives. The choice phase usually involves formal MCDA-GIS interaction in order to develop a solution set of spatial decision alternatives, with integration of decision analytical techniques and GIS functions. In this phase, alternatives are evaluated in order to derive appropriate recommendations. This general framework for MC-SDSS development is based on the general architecture of spatial multicriteria decision-analysis from [12], but presents some changes in the Design Phase, such as the iterative application of the ELECTRE TRI to perform MCDA, and uses an innovative way to define the set of alternatives that are evaluated.

Figure 1 goes about here

\subsection{Problem Definition}

The EDM Region is located in the northwest of Portugal and consists of a set of 10 counties: Viana do Castelo, Barcelos, Esposende, Póvoa de Varzim, Vila Nova de Famalicão, Vila do Conde, Santo Tirso, Trofa, Maia and Matosinhos, with an area of $158,438 \mathrm{~km}^{2}$. This region has 1705 dairy farms with more than 100,000 bovine animals, which produce approximately 1.5 million cubic metres of wastewater (solids and liquids) per year.

The dairy sector has significant economic and social importance to this region. However, this activity has generated numerous environmental problems linked to the high spatial concentration of farms and increasing number of animals, either caused by the volume of effluent generated and related impacts on water and soil, or by conflicts with urban areas. These factors, sometimes associated with insufficient storage capacity and sewage treatment, as well as the misuse of equipment and methods of spreading in the soil, result in contamination of crops and waterways, as well as production of unpleasant odours, among other problems.

As pressure from environmental regulations and surrounding community increases, it is important to build a set of ADs for a better manure management in this region. On the other hand, biogas plants belong to the group of undesirable facilities and are considered as NIMBY (not in my backyard) facilities, whose location presents two main problems to be addressed: (i) social opposition and (ii) a large number of social, economic and environmental data that have to be taken into account [30].

\subsection{Constraints and Factors}

Recently, in Portugal, there has been a concern regarding the problem of evaluation of biogas production using different sources, but there is still no legislation defining the location, characteristics and limitations for installation of this type of plants. In this study, we resorted to Portuguese legislation directed to the installation of similar infrastructures (such as solid waste landfill), European legislation, other studies and the contribution of two experts - an agronomic engineer, specialized in the environmental field and GIS applications (Expert 1), and another agronomic engineer specialized in Photogrammetry and Remote Sensing (Expert 2), who have developed various works in the region in study.

In the present study 20 criteria (attributes) are involved in the methodological process, either as constraints (or exclusionary criteria) or factors (or non-exclusionary criteria).

We consider seven exclusion criteria, defined in Table 1 by Expert 1 that considered legislation about the implementation of landfills, the Municipal Master Plans and other similar 
studies such as $[3,31,32]$. Based on these constraints the GIS obtains independent eligible geographic areas of polygonal shape (referred as polygons from now on) considered as nonexcluded or potentially suitable sites, through basic GIS operations of ESRI ${ }^{\circledR}$ ArcGIS ${ }^{\circledR} 10$ (buffering, boolean logic, etc.) [33]. An additional constraint named "Minimum Area" represents the minimum area of the polygon required for the implementation of a centralized biogas plant. We defined that the implementation of a centralized biogas plant occupies at least one hectare (ha), based on Expert 1 knowledge and other studies as [34]. The final constraint relates to the physical shape of polygons, which sometimes are not realistic options for the implementation of this type of infrastructure. In this work, we use a shape measure including area and perimeter measures - the compactness (or circularity ratio). Involving the Expert 2 about different shape measures and [35], a restriction "Adequate Shape" is defined based on a constraint of each polygon area (represented in Table 1). Considering the constraints set, we obtained a suitability map containing the location alternatives.

Table 1 goes about here

In this study, the criteria factors are defined by the expert who identified three dimensions: an environmental dimension, an economic dimension, and a social and safety dimension. A biogas plant site should be situated as far away as possible from biophysical elements such as water, and other areas with ecological and agricultural value in order to reduce the risk of contamination and to protect the environment. The use, occupancy and type of the soil also should be considered to minimize the impacts on their use and to reduce risks. Moreover, when considering economic feasibility of a candidate site, the proximity to the electricity network, the proximity to roads and the slope of the terrain are important. At the same time, the biogas plant is considered to have a significant impact on the population living within close proximity to the site, due to concerns such as aesthetics, odour, safety, noise, decrease in property value and health hazards. Therefore the plants should be situated at a considerable distance from urban residential, commercial and industrial areas. In this study, we considered 13 criteria factors (Table 2) defined by the two experts, based in their knowledge and in study [32], where some factors (roads, transmission lines, urban areas, water and slope) are considered.

Table 2 goes about here

These factors are mostly quantitative and represented by distances, and so the majority of the derived maps are distance maps. Only two criteria are qualitative ("Occupation and Land Use" and "Agricultural Soils"), given the subjectivity of qualitative criteria, we proceed to its simplification through the use of a rating scale defined by the experts.

\subsection{Outranking Method}

Outranking methods are a type of MCDA methods that are well suited to land suitability assessment and to deal with spatial decision problems since they: (i) permit to consider qualitative evaluation criteria (in addition to quantitative ones) for which preference intervals ratios have no sense; (ii) permit to consider evaluation criteria with heterogeneous scales such that coding them into one common scale would be very difficult or artificial; (iii) avoid the complete compensation between evaluation criteria; and (iv) require a fewer amount of information from the decision maker [36]. But it is also recognized that these methods are subject to computational limitations with respect to the number of decision alternatives [37]. Outranking approaches require a comparison of all pairs of alternatives along each factor defined. In cases where dealing with large raster datasets these methods reach their computational limits quickly.

In this study the previously identified potential sites (polygons) are the location alternatives to be subject to a multi-criteria evaluation process. Each of polygons has a different shape and 
area and the occupied space is not homogeneous for each factor. The MCDA method requires numerical values but it is not possible to associate with each polygon a unique value for each factor. To overcome this difficulty we resort to descriptive statistical values and spatialized scenarios. We apply this process again to new smaller sites inside these classified polygons, created through a vector grid, to obtain a more specified and complete suitability classification.

\subsubsection{Decision Matrix and Spatialized Suitability Scenarios}

In order to obtain a decision matrix indicating the performance of each alternative on each factor, the minimum and maximum values of all factors across each region are computed, using a tool in Spatial Analyst's, the "Zonal Statistics" of ArcGIS®. Although the maximum and minimum values are two extreme measures we consider that using a simple average value as an estimate would be insufficient to address the potentially significant differences between the best and the worst cases.

In order to classify each alternative, the decision matrix is constructed taking into account two scenarios, called "Best" and "Worst" scenarios. The Worst Scenario decision-matrix contains the worst values, i.e. the minimum values of each criterion for each alternative, obtained from the Zonal Statistics tool, if the objective is to maximize, and maximum values, if the objective is to minimize. On the contrary, the Best Scenario decision-matrix contains the maximum values if the objective is to maximize and the minimum values if the objective is to minimize. Thus, two decision matrices associated with two scenarios were obtained, on which the decision rule will be applied. Each of these scenarios has spatial information about each of the factors involved, which is the input for the MCDA method. If the classification is the same in both scenarios, it means that we can classify this alternative in that particular category and so the classification is robust regardless of the location of the plant within this site.

In some polygons there is only one possible location for the biogas plant, whereas in some large polygons there may be several locations where the biogas plant may be implemented. We consider that it is important to study the location of the biogas plant within suitable areas that are comparable in size and that are small enough to be considered homogeneous (i.e. the characteristics of the location should not differ much from one place to another inside a polygon). For this purpose, we create a vector grid that intersects with suitable areas, creating a grid within these sites. The Vector Grid generation process subdivides larger areas into smaller regular polygon cells and allows saving the polygon cells generated as a vector object. For the Grid Generation a tool called ET GeoWizards [38] in ArcGIS® is used. The cell size must be greater than the minimum required area (1 ha) since the grids created in this work will also be considered as possible alternative locations for the biogas plant. In this study, we considered that the cell size of the grid is two hectares. The grids obtained are intersected with some of this suitable polygons and the intersect results from both have to be re-analysed using the constraints related to the minimum area required and the adequate shape (adapted for this step).

\subsubsection{ELECTRE TRI Method}

The chosen MCDA method is ELECTRE TRI, which is specifically devoted to classification problems and has been used by several authors in environmental problems (e.g., $[39,40,41,42,43])$.

ELECTRE TRI has been developed for dealing with the so-called sorting problematic, which sorts a set of alternatives into a set of predefined categories, considering multiple criteria. This assignment of each alternative $a_{k}$ from a set A to a category or class $C_{i}$ is undertaken, based on a comparative study between each alternative and the reference profiles that characterize the limits of each category. To assign each alternative to a category, ELECTRE TRI makes use of the outranking concept, building binary relations among each alternative $a_{k}$ and the profiles $b_{i}$ and $b_{i-1}$ that bound each category $C_{i}$. For the context of this problem, each $a_{k}$ represents a suitable site to be sorted, and each profile $b_{i}$ defines a category 
of suitability. The method assumes that classes are listed in increasing order of preference, e.g., $C_{1}$ is the worst category (least suitable for a location).

ELECTRE TRI builds a valued outranking relation $S$ whose meaning is " $a_{k}$ is at least as good as $b_{i}$ " $[44,45]$, i.e., it defines an index $\sigma\left(a_{k}, b_{i}\right) \in[0,1]$ that represents the degree of credibility of the assertion $a_{k} S b_{i}$. The assertion $a_{k} S b_{i}$ is considered to be valid if $\sigma\left(a_{k}, b_{i}\right) \geq \lambda$, $\lambda$ being a "cutting level" such that $\lambda \in[0.5,1]$, that is defined as the lowest degree of credibility $(\sigma)$ for which we can say that $a_{k}$ outranks $b_{i}[46,47]$.

According to the pessimistic procedure, which is the one most used in practice [46], the alternative $a_{k}$ is assigned to the highest category $C_{i}$ such that $a_{k}$ outranks $b_{i-1}$ (the category's lower bound) and does not outrank $b_{i}$ (the category's upper bound). For further details on the algorithm and concepts of this method, see [44,45,46,49,50,51].

\subsubsection{Decision makers preferences of ELECTRE TRI}

In this work ELECTRE TRI classifies the alternatives according to predefined categories which are: Category 1 - low suitability, Category 2 - medium suitability and Category 3 - high suitability. The criteria (factors) considered are those presented in Table 2. ELECTRE TRI will evaluate land-use suitability according to multiple factors considered by a comparison of the category profiles, in order to classify the most suitable sites for implementation of a biogas plant, with the subjective parameter values (that express preferences) being specified by experts, legislation and other studies. The most important subjective parameters are composed of two reference profiles $\left(b_{1}\right.$ and $\left.b_{2}\right)$. The reference $b_{2}$ defines the set of criteria performance values separating medium and high suitability, whereas reference $b_{1}$ defines the limits separating low and medium suitability. Each alternative is compared with these reference profiles. If an alternative outranks $b_{2}$, its suitability is qualified as high. In an analogous way, its suitability is low if it does not outrank $b_{1}$. If the alternative outranks $b_{1}$ but does not outrank $b_{2}$, its suitability is qualified as medium. The reference profiles set by the expert are presented in Table 3.

Table 3 goes about here

Other subjective parameters are weights $\left(k_{j}\right)$ and three thresholds: indifference $\left(q_{j}\right)$, preference $\left(p_{j}\right)$ and veto $\left(v_{j}\right)$, which are associated with each soft criterion. Weight expresses the relative importance of the criteria. Indifference is the largest difference in performance, for a factor, that may be considered insignificant. Preference is the smallest difference in performance constituting a clear advantage. The veto threshold indicates a difference in performance (discordance) so large that it vetoes an outranking, even if all other criteria agreed to it. In practice, setting a veto threshold allows to specify minimum performances that an alternative has to achieve to reach a certain category, and that cannot be compensated by excellent performances in other criteria. The indifference, preference and veto thresholds, as well as the criteria weights were obtained directly by considering the responses of experts, as presented in Table 4. The cutting level considered was $\lambda=0.60$ (in the absence of veto, the criteria supporting an outranking must represent at least $60 \%$ of the total criteria weights).

Table 4 goes about here

\subsubsection{Iterative application of ELECTRE TRI}

We begin by applying ELECTRE TRI twice to classify the polygons according to the Best and Worse scenarios, using two decision matrices. If the ELECTRE TRI results (classification) are the same in both scenarios, it means that we can classify this site in the particular category and so their classification is obtained regardless of the location of the biogas plant within this suitable site. In case the classification is different in both scenarios then we create a vector grid that intersects with suitable sites (polygons) that not are classified yet. ELECTRE TRI is applied 
again, considering now the intersected grid cells as alternatives and the same parameters defined previously. Again, two matrices for each scenario (Worst and Best) and the classification of each one of grids according to defined categories are obtained but, since the areas are smaller, it is expected that the differences between the two scenarios decrease. At the end, the most suitable alternatives are identified and a map of the most suitable sites is obtained.

\section{Results}

\subsection{Obtaining the suitability map}

This methodological approach began by considering the seven exclusion criteria defined to obtain potentially suitable sites. In this case study, 521 polygons (independent geographic regions) were obtained. However, only 380 polygons have the minimum area required, i.e., 141 polygons were excluded for having an area smaller than 1 ha. Taking into consideration the adequate shape constraint, 62 polygons that do not fulfil the requirements described above, were excluded. After applying these three constraints, 318 sites were found to be suitable for locating a biogas plant, with areas from 1 ha to 35.4 ha.

The suitability map (Figure 2), corresponding to the condition of the study that represents the suitability or unsuitability of a certain place, shows that a large portion of the area under analysis is unsuitable due to one or more constraints.

Figure 2 goes about here

\subsection{Application of ELECTRE TRI considering the suitable polygons as alternatives}

In this phase ELECTRE TRI was applied to 318 sites classified to be suitable as alternatives, for each scenario (Best and Worst) in order to classify each of the alternatives. The following results were obtained (Figure 3):

- 245 alternatives (suitable polygons) were classified as Category 1, i.e., low suitability;

- 9 alternatives were classified as Category 2, i.e., medium suitability;

- 1 alternative was classified as Category 3 , i.e., high suitability;

- 22 options ranging from low to medium suitability (Category 1 in the worst scenario and Category 2 in the best scenario, defined as Category 1-Category 2);

- 20 alternatives vary between low and high suitability (Category 1 in worst scenario and Category 3 in the best scenario, defined as Category 1-Category 3);

- 21 alternatives ranging from medium to high suitability (Category 2 in worst scenario and Category 3 in the best scenario, defined as Category 2-Category 3).

Figure 3 goes about here

This means that out of 318 alternatives, 255 obtain the same category in both scenarios and 63 alternatives are not definitively classified. To obtain a more detailed classification of the areas for which the two scenarios do not coincide, these areas were partitioned by means of grids.

\subsection{Application of ELECTRE TRI considering vector grids as alternatives}

For a better classification of the 63 polygons not definitively classified, having areas between 1.1 ha and 35.4 ha, in the second phase a sub-division of these sites with a vector grid was considered in order to obtain a more specific classification. In this study, quadrangular grids with two hectares were built using the ET GeoWizards tool. 
By intersecting this quadrangular grid with the 63 unclassified suitable sites, 513 grids were obtained. It is also necessary to require that each of them has the required minimum area of 1ha, eliminating 389 grids. This yields 124 grids with the required area but some of them do not have the appropriate shape for the implementation of biogas plants. By imposing the condition that compactness $\geq 0.40$, we obtained 109 grids, i.e., 15 have been eliminated.

Using the ELECTRE TRI for both scenarios (Worst and Best), taking into consideration these 109 Vector grids as alternatives, the following results were obtained (Figure 4):

- 31 alternatives (suitable sites) are classified as Category 1, i.e., low suitability;

- 11 alternatives are classified as Category 2, i.e., medium suitability;

- 1 alternative is classified as Category 3, i.e., high suitability;

- 31 options ranging from low to medium suitability;

- 3 alternatives vary between low and high suitability;

- 32 alternatives ranging from medium to high suitability.

Figure 4 goes about here

Taking into consideration these restrictions (minimum size and adequate shape) and the fact that the creation of the grids by ET GeoWizards is automated, some of the 63 suitable sites do not contain grids. Fifteen suitable sites are in this situation: five are classified as category 1 in the worst scenario and category 2 in the best; four are classified as category 1 in the worst scenario and category 3 in the best and seven are classified as category 2 in the worst scenario and category 3 in the best.

Overall, we obtained:

- 39 sites classified as Medium-High suitability (classified as category 2 in the worst scenario and category 3 in the best scenario), of which 32 appeared as grids and 7 as suitable polygons;

- 2 sites classified as High Suitability are added to this: one being a grid and the other one a suitable polygon. The area of the most suitable sites varies between 1.038 and 2.215 ha.

These 41 sites deemed to be the most interesting ones for locating biogas plants are spread over eight counties (Figure 5): Barcelos, Esposende, Maia, Póvoa de Varzim, Trofa, Viana do Castelo, Vila do Conde and Vila Nova de Famalicão, and about $46 \%$ of sites are located in the county of Vila do Conde, $19.5 \%$ in the county of Póvoa de Varzim, 12.2\% in Barcelos and $7.32 \%$ in Esposende. In addition to polygon distributing across counties, we also analysed the distribution across parishes (Table 5).

Figure 5 and Table 5 goes about here

\subsection{Discussion}

The results show that this GIS-based model, by integrating both spatial data and non-spatial information, is capable of providing a broad-scale and multidimensional view on the potential bio-energy systems development in the area of study to account for constraints as well as economic, environmental and social factors.

The suitability of development projects depends, to a large extent, on the integration of local knowledge with scientific inputs from the stakeholders (e.g. planners, local governments, electric utilities, dairy farmers and other interested parties) in the decision-making process, so the involvement of more experts and decision makers will be necessary to eventually implement decisions based on this type of approach.

The main limitation of this work is that the amount and location of animal waste sources to be used by a biogas plant was not taken into account. This can be addressed by facility location optimization models able to consider the amount of waste needing to be processed on each farm and the road network. Such models usually have a large size. Nevertheless, the work developed 
in this paper allows such a location model to be much easier to solve, since it already identifies a small number of candidate locations.

\section{Conclusions}

Multicriteria Spatial Decision Support Systems, with integration of GIS and MCDA, constitute a very promising research line in the broad field of suitability assessments of land-use and, particularly, in that of undesirable facilities location problems, thanks to the greater effectiveness and efficiency gained by the spatial decision-making process. This study presents an innovative approach to the GIS/ELECTRE TRI methodology, in consideration of two scenarios and the iterative application of the method, (firstly) considering suitable sites as alternatives and (secondly) vector grid cells as alternatives, and considering the variability of the site's geographical characteristics from one zone to another (factor homogeneity inside each alternative location).

Using the resulting suitability map the decision makers can make decisions based on better knowledge of land-use suitability. The domain experts assumed a technical (vs. political) perspective when setting the ELECTRE TRI parameters. Reaching a final decision can benefit from involving the local authorities and other stakeholders, who may weigh differently the evaluation criteria and may bring concerns of a more political nature. Therefore, although land plots excluded by the hard constraints or poorly classified by the ELECTRE TRI model are clearly alternatives to be excluded, land plots with a good classification are not necessarily politically acceptable alternatives for siting a plant.

Acknowledgement. This work was partially supported by FCT grant PEstOE/EEI/UI0308/2014 and project EMSURE (CENTRO 07-0224-FEDER-002004).

\section{References}

[1] Dagnall S, Hill J, Pegg D. Resource mapping and analysis of farm livestock manures - assessing the opportunities for biomass-to-energy schemes. Bioresource Technol 2000; 71(3): 225-4.

[2] Taleghani G, Kia AS. Technical-economical analysis of the Saveh biogas power plant. Renew Energ 2005; 30(3): 441-6.

[3] Ma J, Scott, NR, DeGloria S, Lembo AJL. Siting analysis of farm-based centralized anaerobic digester systems for distributed generation using GIS. Biomass Bioenerg 2005; 28(6): 591-0.

[4] DGEG. Balanço Energético Nacional (National Energy Balance). Direç̧ão Geral de Energia e Geologia 2010, Lisboa (in Portuguese).

[5] Ferreira M, Marques IP, Malico I. Biogas in Portugal: Status and public policies in a European context. Energ Policy 2012; 43: 267-4.

[6] Collins MG, Steiner FR, Rushman MJ. Land-use suitability analysis in the United States: historical development and promising technological achievements. Environ Manage 2001; 28(5): 611-21.

[7] Sener B, Süzen ML, Doyuran V. Landfill site selection by using geographic information systems. Environ Geol 2006; 49(3): 376-88.

[8] Malczewski J. Review Article GIS-based multicriteria decision analysis: a survey of the literature. Int J Geogr Inf Sci 2006; 20(7): 703-26.

[9] Jankowski P. Integrating geographical information systems and multiple criteria decision-making methods. Int J Geogr Inf Syst 1995; 9(3): 251-73.

[10] Carver SJ. Integrating multi-criteria evaluation with geographical information systems. Int $\mathbf{J}$ Geogr Inf Syst 1991; 5(3): 321-39.

[11] Belton V, Stewart T. Multiple Criteria Decision Analysis: An Integrated Approach, Kluwer Academic, Dordrech; 2002. 
[12] Malczewski J. GIS and Multicriteria Decision Analysis. Wiley, New York; 1999.

[13] Church RL. Geographical information systems and location science. Comput Oper Res 2002; 29(6): 541-62.

[14] Janssen R, Rietveld P. Multicriteria analysis and geographical information systems: An application to agriculture land-use in Netherlands. In: Scholten HJ, Stillwell JCH, editors. Geographical information systems for urban and regional planning. Dorchecht: Kluwer Academic Publishers; 1990, p. 129-139.

[15] Joerin F, Thériault M, Musy A. Using GIS and outranking multicriteria analysis for land-use suitability assessment. Int J Geogr Inf Sci 2001; 15(2): 153-74.

[16] Pereira JMC, Duckstein L. A multiple criteria decision-making approach to GIS-based land suitability evaluation. Int J Geogr Inf Syst 1993; 7(5): 407-24.

[17] Jankowski P, Richard L. Integration of GIS-based suitability analysis and multicriteria evaluation in a spatial decision support system for route selection. Environ Plann B 1994; 21(3): 323-40.

[18] Malczewski J. GIS-based land-use suitability analysis: a critical overview. Prog Plann 2004; 62(1): 3-65.

[19] Jafari S, Zaredar N. Land Suitability Analysis using Multi Attribute Decision Making Approach. IJESD 2010; 1(5): 441-5.

[20] Passuello A, Cadiach O, Perez Y, Schuhmacher M. A spatial multicriteria decision making tool to define the best agricultural areas for sewage sludge amendment. Environ Int 2011; 38(1): 1-9.

[21] Holzmueller EJ, Gaskins MD, Mangun JC. A GIS approach to prioritizing habitat for restoration using Neotropical migrant songbird criteria. Environ Manage 2011; 48(1):150-7.

[22] Tavares G, Zsigraiová, Z, Semiao V. Multi-criteria GIS-based siting of an incineration plant for municipal solid waste. Waste Manage 2011;31(9-10):1960-72.

[23] Ferretti V, Pomarico S. Integrated sustainability assessments: a spatial multicriteria evaluation for siting a waste incinerator plant in the Province of Torino (Italy). Environ Dev Sustain 2012; 14(5): 84367.

[24] Alçada-Almeida L., Coutinho-Rodrigues J., Current J. A multiobjective modeling approach to locating incinerators. Socio Econ Plan Sci 2009; 43: 111-0.

[25] Sanchez-Lozano JM, Teruel-Solano J, Soto-Elvira, Garcia-Cascales MS. Geographical Information Systems (GIS) and Multi-Criteria Decision Making (MCDM) methods for the evaluation of solar farms locations: Case study in south-eastern Spain. Renew Sust Energ Rev 2013; 24: 544-56.

[26] Aydin NY, Kentel E, Duzgun HS. GIS-based site selection methodology for hybrid renewable energy systems: A case study from Western Turkey. Energ Convers Manage 2013; 70: 90-106.

[27] Haddad MA, Anderson PF. A GIS methodology to identify potential corn stover collection locations. Biomass Bioenerg 2008; 32(12): 1097-108.

[28] Dael MV, Passel SV, Pelkmans L, Guisson R, Swinnen G, Schreurs E. Determining potential locations for biomass valorization using a macro screening approach. Biomass Bioenerg 2012, 45: 17586.

[29] Simon HA. The New Science of Management Decision, Harper and Brothers, New York; 1960.

[30] Ferretti V. A Multicriteria Spatial Decision Support System Development for Siting a Landfill in the Province of Torino (Italy). Multi-Criteria Decision Analysis 2011; 18: 231-52.

[31] Perpiña C, Alfonso D, Pérez- Navarro, Peñalvo E, Vargas C, Cárdenas R. Methodology based on Geographic Information Systems for biomass logistics and transport optimisation. Renew Energ 2009; 34 (3): 555-565.

[32] Sultana A, Kumar A. Optimal siting and size of bioenergy facilities using geographic information system. Appl Energ 2012; 94: 192-1.

[33] ESRI, ArcGIS 10.0 Help Library [cited 2014 Out 11]. Available from: http://resources.arcgis.com/en/home/. 
[34] Seadi TA, Rutz D, Prassl H, Köttner M, Finsterwalder T. Biogas Handbook. University of Southern Denmark Esbjerg; 2008.

[35] van der Werff HMA, van der Meer FD. Shape - based classification of spectrally identical objects. ISPRS J Photogramm Remote Sens 2008; 63 (2): 251-8.

[36] Chakhar S, Mousseau V. GIS-based multicriteria spatial modeling generic framework. Int J Geogr Inf Sci 2008; 22(11-12): 1159-96.

[37] Marinoni O. A discussion on the computational limitations of outranking methods for land-use suitability assessment. Int J Geogr Inf Sci 2006; 20(1): 69-87.

[38] ET GeoWizards [cited 2014 Jan 11]. Available from: http://www.ianko.com/ET_GeoWizards/gw_main.htm.

[39] Arondel C, Girardin P. Sorting cropping systems on the basis of their impact on groundwater quality. Eur J Oper Res 2000; 127(3): 467-82.

[40] Madlener R, Antunes CH, Dias LC. Assessing the performance of biogas plants with multicriteria and data envelopment analysis. Eur J Oper Res 2009; 197(3): 1084-94.

[41] Brito AJ, Almeida AT, Mota CMM. A multicriteria model for risk sorting of natural gas pipelines based on ELECTRE TRI integrating Utility Theory. Eur J Oper Res 2010; 200(3): 812-21.

[42] Georgopoulou E, Sarafidis Y, Mirasgedis S, Zaimi S, Lalas DP. Applications a multiple criteria decision-aid approach in defining national priorities for greenhouse gases emissions reduction in the energy sector. Eur J Oper Res 2003; 146(1): 199-15.

[43] Raju K, Duckstein L, Arondel C. Multicriterion Analysis for Sustainable Water Resources Planning: A Case Study in Spain. Water Resour Manag 2000; 14(6): 435-56.

[44] Yu W. ELECTRE TRI: Aspects méthodologiques et manuel d'utilisation. Document du LAMSADE No. 74, Université Paris-Dauphine; 1992.

[45] Roy B, Bouyssou D. Aide multicritère à la decision: méthodes et cas, Economica, Paris; 1993.

[46] Figueira J, Mousseau V, Roy B. ELECTRE Methods. In: Greco S, editor. Multiple Criteria Decision Analysis: state of the art surveys, Springer; 2005, p. 134-162.

[47] Roy B. Méthodologie multicritère d'aide à la decision. Economica, Paris; 1985.

[48] Dias L, Mousseau V, Figueira J, Clímaco J. An aggregation/disaggregation approach to obtain robust conclusions with ELECTRE TRI. Eur J Oper Res 2002; 138(2):332-348. 1996.

[49] Roy B. Multicriteria Methodology for Decision Aiding. Dordrecht: Kluwer Academic Publishers;

[50] Mousseau V, Dias L. Valued outranking relations in ELECTRE providing manageable disaggregation procedures. Eur J Oper Res 2004; 156(2): 467-482.

[51] Figueira JR, Greco S, Roy B, Slowinski R. ELECTRE Methods: Main Features and Recent Developments. In Zopounidis C, Pardalos P, editors. Handbook of Multicriteria Analysis, New York, USA: Springer; 2010, p. 133-162. 


\begin{tabular}{|c|c|c|}
\hline & Constraints & Description \\
\hline \multirow{9}{*}{ 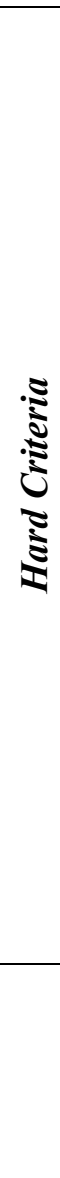 } & $\begin{array}{l}\text { National ecological } \\
\text { reserves, Natura } 2000 \\
\text { and Protected Areas }\end{array}$ & $\begin{array}{l}\text { Areas classified as National Ecological Reserve, Protected } \\
\text { Areas and Natura } 2000 \text { are excluded from the analysis. }\end{array}$ \\
\hline & Hydrographic network & $\begin{array}{l}\text { To exclude areas which contain or are less than } 150 \text { meters } \\
\text { away from water lines }\end{array}$ \\
\hline & Roads and Railway & $\begin{array}{l}\text { To exclude areas which contain or are less than } 70 \text { meters } \\
\text { away from motorways, regional roads, national roads and rail } \\
\text { network. }\end{array}$ \\
\hline & Slopes & $\begin{array}{l}\text { To exclude areas with slopes greater than } 15 \% \text { or less than } \\
2.5 \% \text { (avoid areas prone to flooding and high costs of } \\
\text { construction) }\end{array}$ \\
\hline & $\begin{array}{ll}\text { Urban, Industrial } & \text { and } \\
\text { Commercial } & \text { and } \\
\text { Infrastructure } & \end{array}$ & $\begin{array}{l}\text { To exclude areas which contain or are less than } 200 \text { meters } \\
\text { away from Urban, Industrial and Commercial and } \\
\text { Infrastructure areas (Airports, port areas and other equipment). }\end{array}$ \\
\hline & Built-up areas & $\begin{array}{l}\text { To exclude Buildings (isolated type, as residential } \\
\text { building) }\end{array}$ \\
\hline & Electricity Grid & $\begin{array}{l}\text { To exclude areas whose distance to the Very High Voltage } \\
\text { electrical lines is less than } 200 \text { meters, the distance to High } \\
\text { Voltage lines is less than } 100 \text { meters and the distance to } \\
\text { Medium Voltage lines is less than } 50 \text { meters (for security } \\
\text { reasons). }\end{array}$ \\
\hline & Minimum Area & $\begin{array}{l}\text { Potential sites must have an area of at least one hectare (ha) for } \\
\text { implementation of a biogas plant. }\end{array}$ \\
\hline & Adequate Shape & $\begin{array}{l}\text { Exclude polygons that verify the following condition: } \\
(1 \leq \text { area }(\text { ha }) \leq 1.5 \text { and compactness }<0.45) \text { or } \\
(1.5<\text { area }(\text { ha })<2.5 \text { and compactness }<0.25)\end{array}$ \\
\hline
\end{tabular}

Table 1. Description of the constraints defined in the suitability analysis. 


\begin{tabular}{|l|l|l|l|}
\hline Type & Name & \multicolumn{1}{|c|}{ Factors } & \multicolumn{1}{|c|}{ Objective } \\
\hline \multirow{4}{*}{ Environmental } & F1 & Distance to the National Ecological Reserve & Maximize \\
\cline { 2 - 4 } & F2 & Distance to Protected Habitats (Natura 2000 and Protected Areas) & Maximize \\
\cline { 2 - 4 } & F3 & Distance to the National Agricultural Reserve & Maximize \\
\cline { 2 - 4 } & F4 & Distance to Hydrographic Network & Maximize \\
\cline { 2 - 4 } & F5 & Occupation and Land Use (qualitative assessment of adequacy) & Maximize \\
\cline { 2 - 4 } & F6 & Agricultural Soils (qualitative assessment of adequacy) & Maximize \\
\hline \multirow{5}{*}{ Economic } & F7 & Slope (in \%) & Minimize \\
\cline { 2 - 4 } & F8 & Distance to Highways, Regional and National Roads & Maximize \\
\cline { 2 - 4 } & F9 & Distance to the Municipal Roads and Paths & Minimize \\
\cline { 2 - 4 } & F10 & Distance to Electricity Grid - Medium Voltage Lines & Minimize \\
\cline { 2 - 4 } $\begin{array}{l}\text { Social } \\
\text { Safety }\end{array}$ & F11 & Distance to Electricity Grid - High Voltage & Minimize \\
\cline { 2 - 4 } & F12 & Distance to Urban, Industrial, Commercial and Infrastructure & Maximize \\
\cline { 2 - 4 } & F13 & Distance to the built-up areas & Maximize \\
\hline
\end{tabular}

Table 2. Description of the factors defined in the suitability analysis.

\begin{tabular}{|c|c|c|c|c|c|c|c|c|c|c|c|c|c|}
\hline & F1 & F2 & F3 & F4 & F5 & F6 & F7 & F8 & F9 & F10 & F11 & F12 & F13 \\
\hline$b_{2}$ & 250 & 250 & 200 & 350 & 3 & 4 & 6 & 250 & 150 & 150 & 150 & 600 & 600 \\
\hline$b_{1}$ & 50 & 50 & 0 & 200 & 2 & 2 & 12 & 150 & 250 & 250 & 250 & 400 & 400 \\
\hline
\end{tabular}

Table 3. Reference profiles.

\begin{tabular}{|c|c|c|c|c|c|c|c|c|c|c|c|c|c|}
\hline & F1 & $\mathrm{F} 2$ & $\mathrm{~F} 3$ & $\mathrm{~F} 4$ & F5 & F6 & F7 & $\mathrm{F} 8$ & F9 & F10 & F11 & F12 & F13 \\
\hline$q_{j}$ & 25 & 25 & 15 & 50 & 0 & 0 & 2 & 20 & 20 & 50 & 50 & 50 & 50 \\
\hline$p_{j}$ & 50 & 50 & 35 & 100 & 1 & 1 & 4 & 50 & 50 & 100 & 100 & 100 & 100 \\
\hline V & 230 & 230 & 200 & 200 & 2 & 3 & 9 & 150 & 350 & 250 & 250 & 400 & 400 \\
\hline$k_{i}$ & 0.075 & 0.075 & 0.10 & 0.10 & 0.05 & 0.10 & 0.10 & 0.05 & 0.05 & 0.05 & 0.05 & 0.10 & 0.10 \\
\hline
\end{tabular}

Table 4. Indifference, preference, veto thresholds and weights. 


\begin{tabular}{|c|c|}
\hline BARCELOS & 5 \\
\hline BARQUEIROS & 2 \\
\hline GALEGOS (SANTA MARIA) & 2 \\
\hline GAMIL & 1 \\
\hline ESPOSENDE & 3 \\
\hline ANTAS & 2 \\
\hline VILA CHA & 1 \\
\hline MAIA & 1 \\
\hline GEMUNDE & 1 \\
\hline POVOA DE VARZIM & 8 \\
\hline ARGIVAI & 1 \\
\hline LAUNDOS & 5 \\
\hline TERROSO & 2 \\
\hline TROFA & 2 \\
\hline BOUGADO (SANTIAGO) & 1 \\
\hline MURO & 1 \\
\hline VIANA DO CASTELO & 2 \\
\hline NEIVA & 2 \\
\hline VILA DO CONDE & 19 \\
\hline AZURARA & 1 \\
\hline FAJOZES & 5 \\
\hline GIAO & 11 \\
\hline GUILHABREU & 1 \\
\hline RETORTA & 1 \\
\hline VILA NOVA DE FAMALICAO & 1 \\
\hline CARREIRA & 1 \\
\hline Total & 41 \\
\hline
\end{tabular}

Table 5. Distribution of the most Suitable Sites by Parishes. 


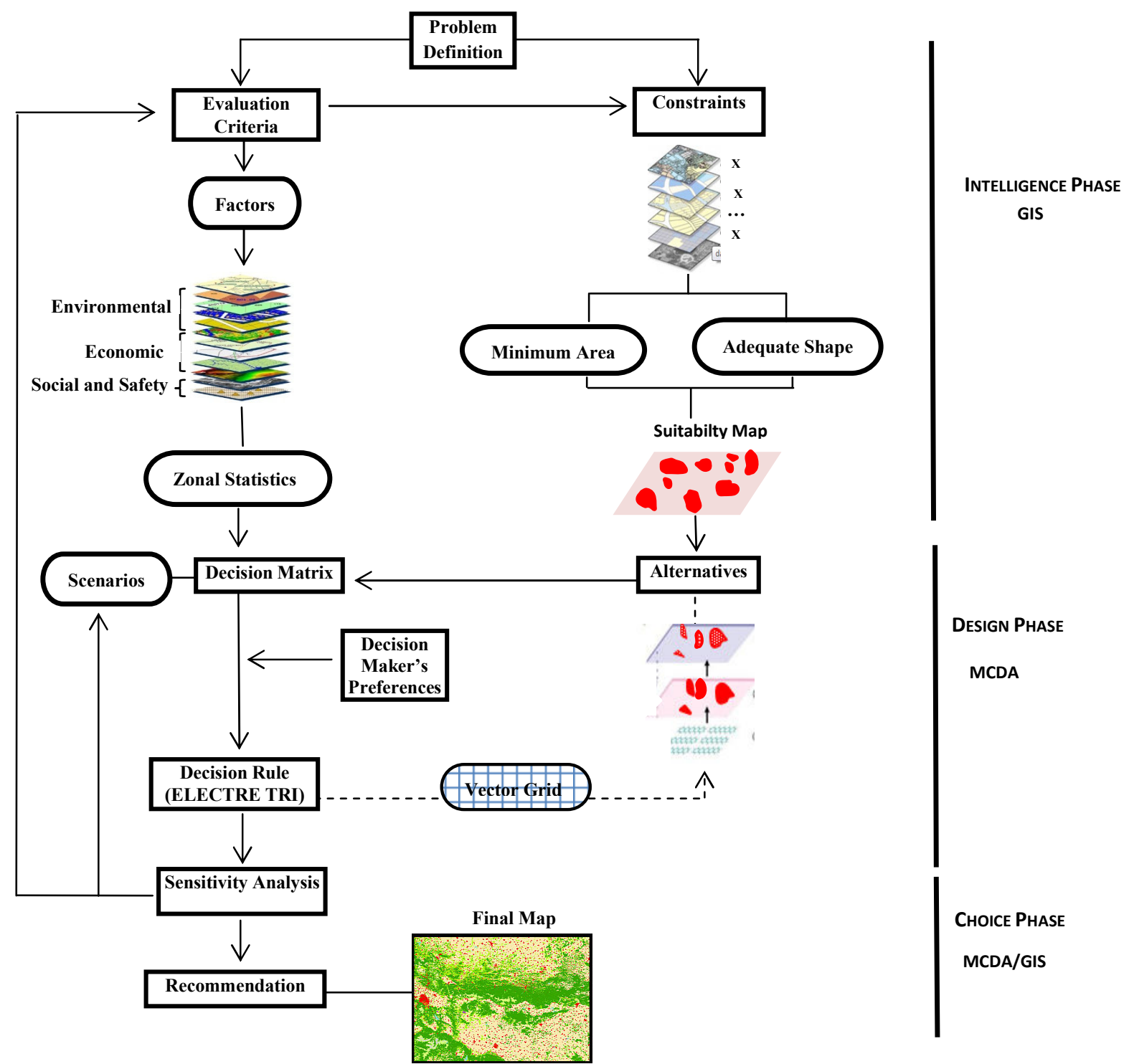

Figure 1. The decision flowchart for the spatial multicriteria analysis methodology. 


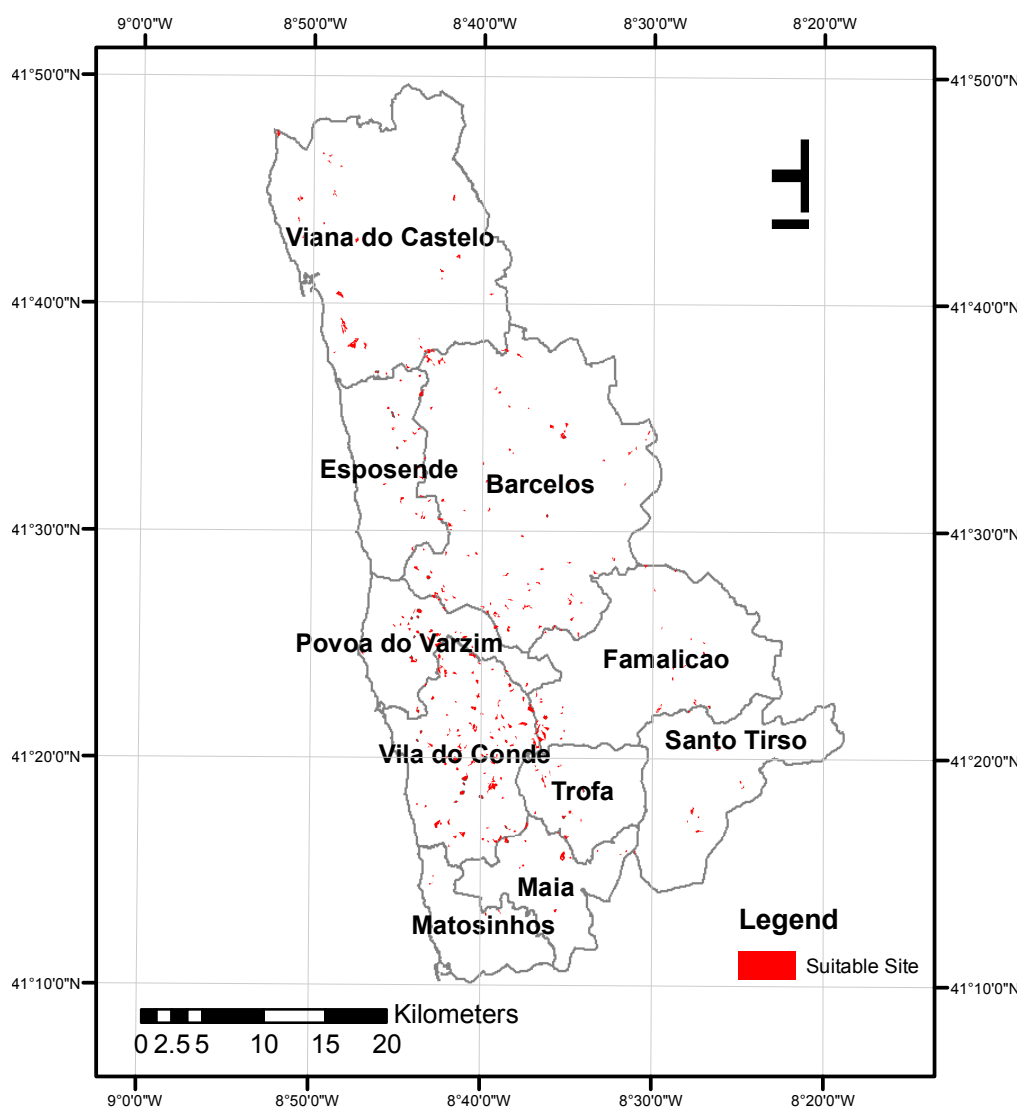

Figure 2. Suitability Map obtained after applying the constraints set. 


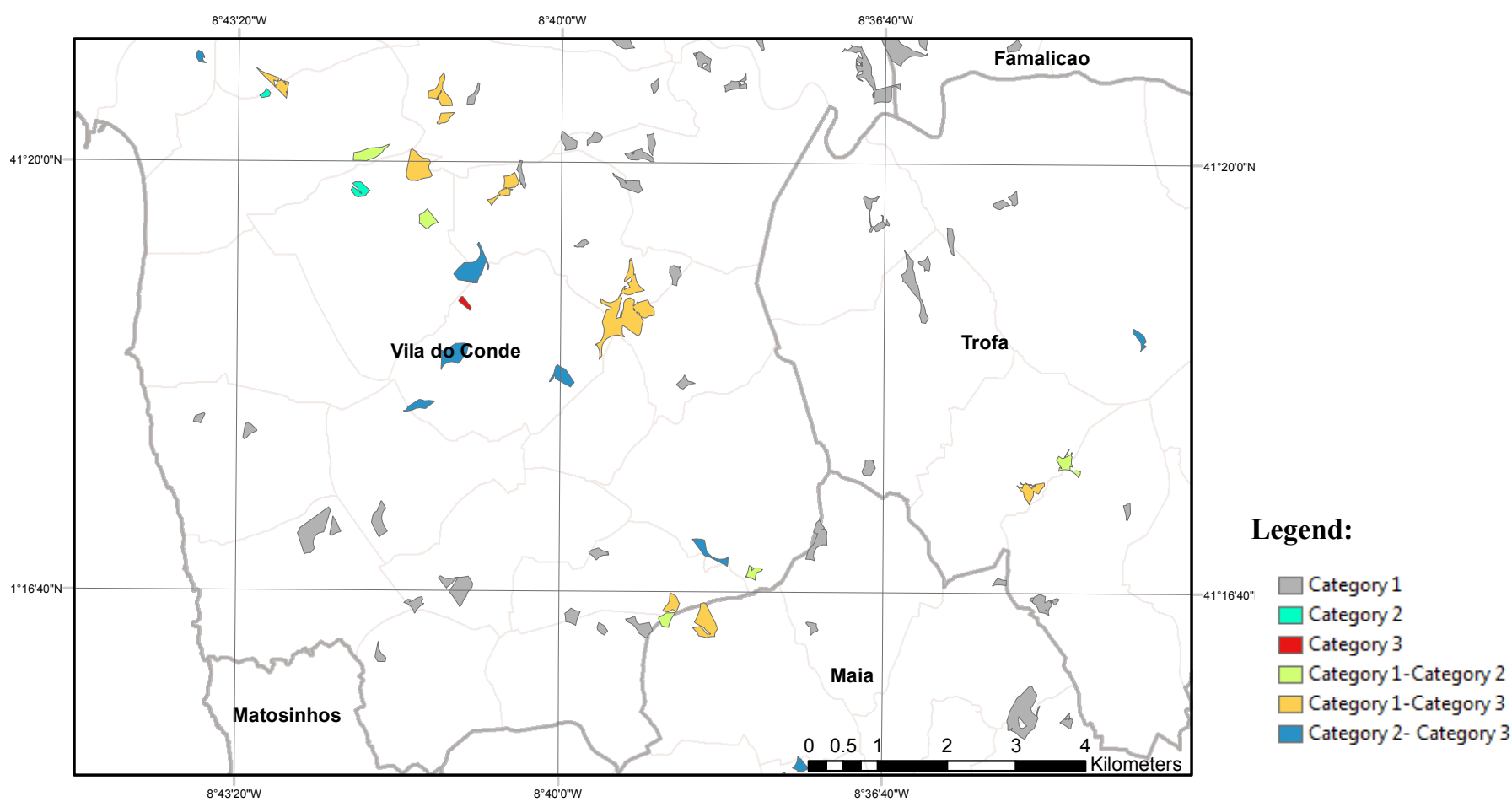

Figure 3. Classification of the polygons meeting the constraints, considering the best and worst values for each polygon (map detail). 


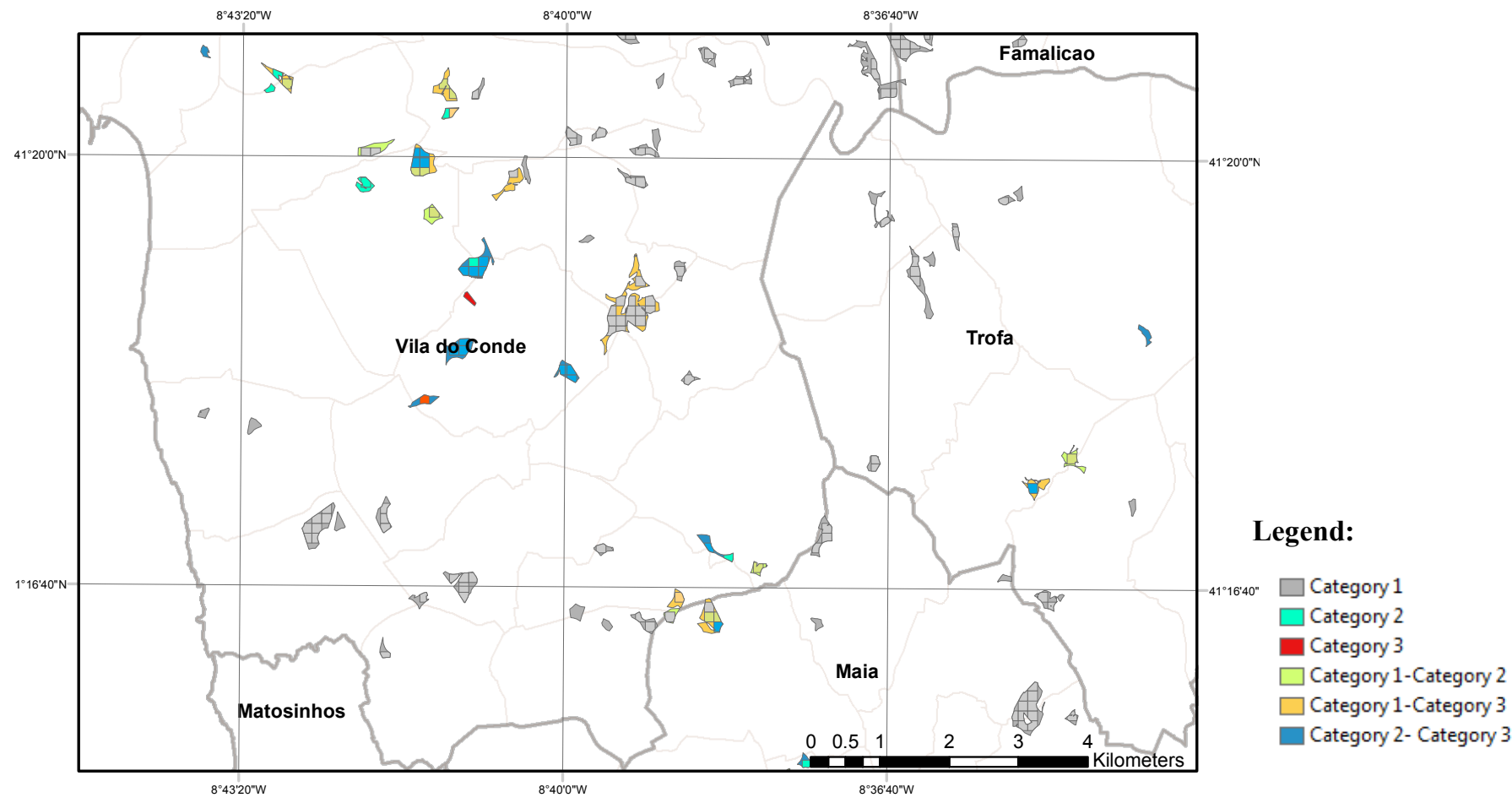

Figure 4. Classification of the smaller areas (vector grid), considering the best and worst values for each site (map detail). 


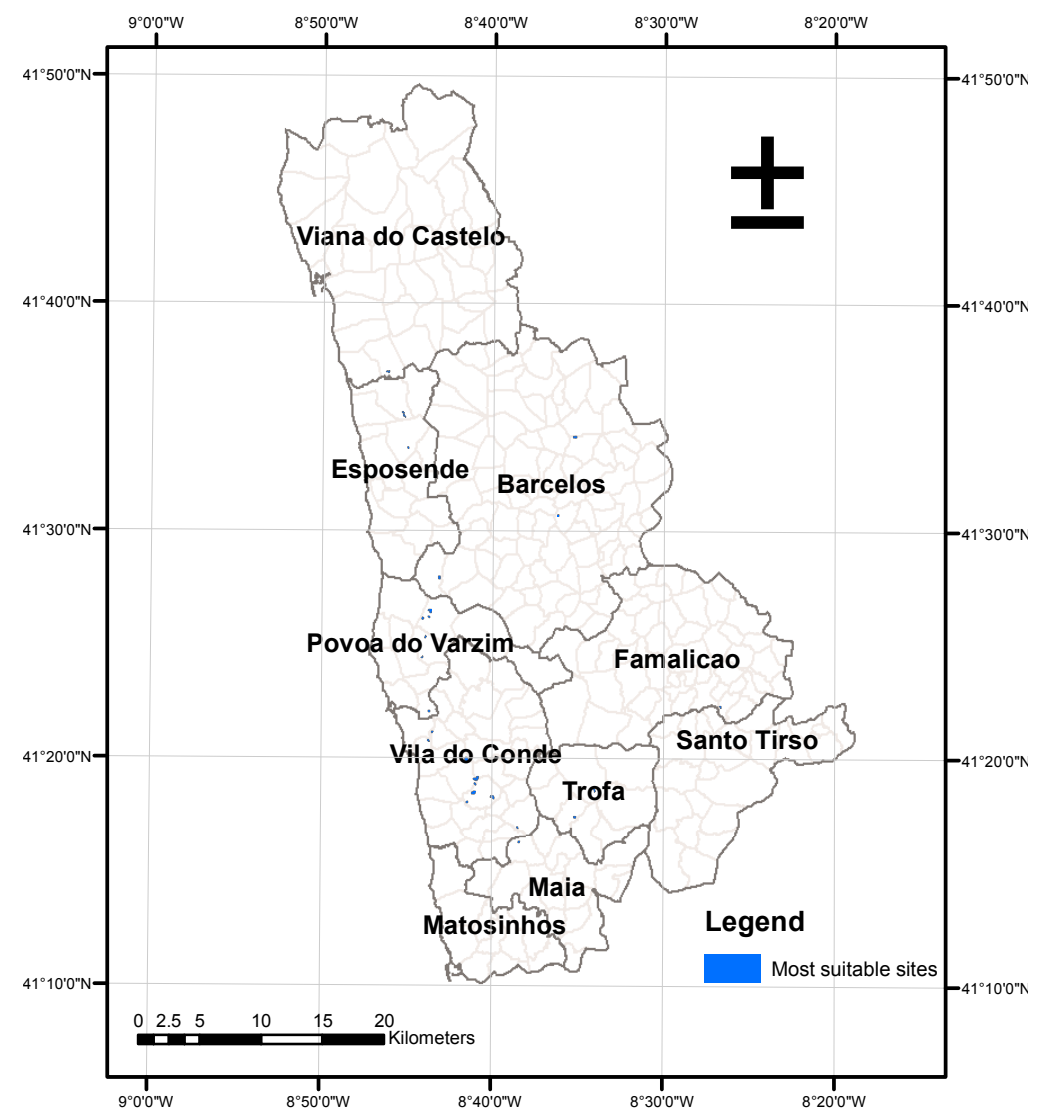

Figure 5. Final map of the most suitable sites for siting biogas plant. 